\title{
Ectopic Tubal Molar Pregnancy: A Case Report
}

\author{
Hadja Maimouna Barro Daff ${ }^{*}$, Dibor Niang², Aïssatou Mbodji1, Ibrahim Donigolo', \\ Moussa Diallo1,3, Abdoul Aziz Diouf ${ }^{1,3}$, Youssoupha Toure', Khalifa Babacar Mansour Fall', \\ Alassane Diouf 1,3 \\ ${ }^{1}$ Gynecological and Obstetric Clinic, Public Institution Aristide-Le Dantec Hospital, Cheikh Anta Diop University of Dakar, \\ Dakar, Senegal \\ ${ }^{2}$ Anatomopathology Laboratory, Gaston Berger University Hospital Center, Saint Louis, Senegal \\ ${ }^{3}$ Department of Obstetrics and Gynecology, Pikine University Hospital, Thiaroye Pikine, Senegal \\ Email: *hmbdaff@gmail.com
}

How to cite this paper: Daff, H.M.B., Niang, D., Mbodji, A., Donigolo, I., Diallo, M., Diouf, A.A., Toure, Y., Fall, K.B.M. and Diouf, A. (2021) Ectopic Tubal Molar Pregnancy: A Case Report. Open Journal of $\mathrm{Ob}$ stetrics and Gynecology, 11, 973-977. https://doi.org/10.4236/ojog.2021.118092

Received: July 3, 2021

Accepted: August 7, 2021

Published: August 10, 2021

Copyright (C) 2021 by author(s) and Scientific Research Publishing Inc. This work is licensed under the Creative Commons Attribution International License (CC BY 4.0).

http://creativecommons.org/licenses/by/4.0/

\begin{abstract}
Background: Molar pregnancy is a rare condition; its ectopic form is even rarer occurring in 1.5 per 1,000,000 pregnancies. Aim: We report a case of ectopic molar pregnancy located in the fallopian tube and draw attention to the importance of systematic histological examination in any ectopic pregnancy. Case report: A 32-year-old primigravida woman presented with metrorrhagia in a context of about 2 months of amenorrhea. An ectopic pregnancy was diagnosed by ultrasonography. A Laparotomy was performed and a ruptured left ampullary ectopic pregnancy was found, and a total left salpingectomy was performed. The pathologic examination and the histological examination show an aspect of a partial molar ectopic tubal pregnancy. Conclusion: Ectopic molar pregnancy is a rare entity, its diagnosis requires histological confirmation. Beta-HCG monitoring is the essential tool for monitoring the postoperative evolution.
\end{abstract}

\section{Keywords}

Ectopic Pregnancy, Hydatidiform Mole, Fallopian Tubes

\section{Introduction}

Ectopic pregnancy occurs mainly at the Fallopian tube (98\% of cases). Molar pregnancy or hydatidiform mole is the most frequent entity of gestational trophoblastic diseases. It is a rare pathology with an incidence of occurrence of 1 per 1000 pregnancies [1]. It develops in the vast majority of cases in the uterine cavity but can occur in any site. Its extra uterine form (molar EP) remains rare, however, with an incidence of 1.5 per 1,000,000 pregnancies [2] [3]. 
We report a case of ectopic molar pregnancy located in the fallopian tube.

\section{Case Report}

A 32-year-old female patient, primigravida, with no particular pathological history, was seen in the service for abdominal pain associated with metrorrhagia in a context of about 2 months of amenorrhea. The clinical examination revealed a good general condition, a sensitive abdomen with signs of peritoneal irritation. Vaginal examination revealed an enlarged uterus and a left latero-uterine mass sensitive to touch. Pelvic ultrasound revealed an enlarged endometrium, a left juxta-ovarian mass associated with a moderate amount of peritoneal effusion. A urine pregnancy test was then performed and came back positive. The blood count showed an anemia of $8.8 \mathrm{~g} / \mathrm{dl}$. The diagnosis of an ectopic pregnancy was made and a laparotomy was indicated and performed. Exploration revealed a ruptured left ampullary ectopic pregnancy measuring $5 \times 2 \mathrm{~cm}$ with moderate hemoperitoneum. The homolateral ovary and contralateral adnexa were unremarkable. The rest of the abdomen was unremarkable. A total left salpingectomy was performed and the specimen sent for anatomopathological examination. The postoperative course was uneventful. The patient was discharged on day 3 of the operation.

Macroscopically, the tube was dilated. Its surface was irregularly jagged. It measured $5 \mathrm{~cm}$ in length and $2 \mathrm{~cm}$ in size. The section showed a lumen filled with necrotic material.

Histological examination showed a ruptured tube wall containing trophoblastic ovarian debris with molar-type chorionic villi. Some villi had edematous, hydropic axes partially lined with hyperplastic trophoblast while other villi were small and involutional. The serosa was the site of exudative inflammation (Figures 1-3). In view of these histological aspects, the diagnosis retained was a partial mole on ruptured tubal pregnancy.

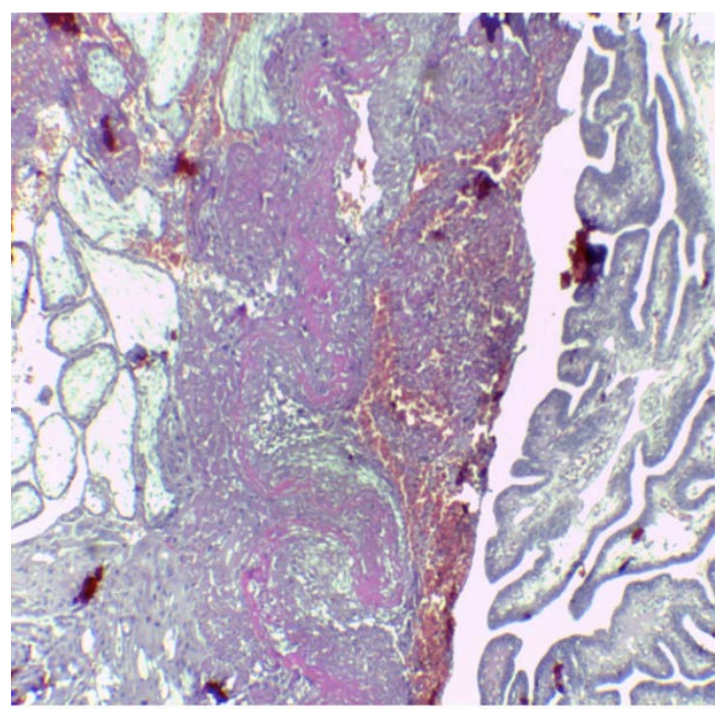

Figure 1. Presence of ovular material (left) in the lumen of the tube (right). 


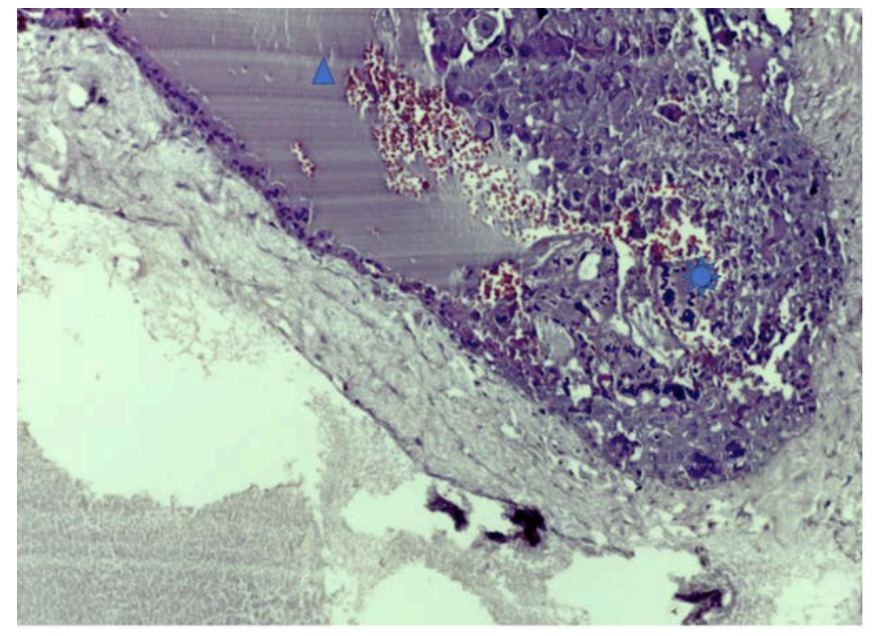

Figure 2. Hydropic chorionic villosities partially bordered by trophoblastic hyperplasia.

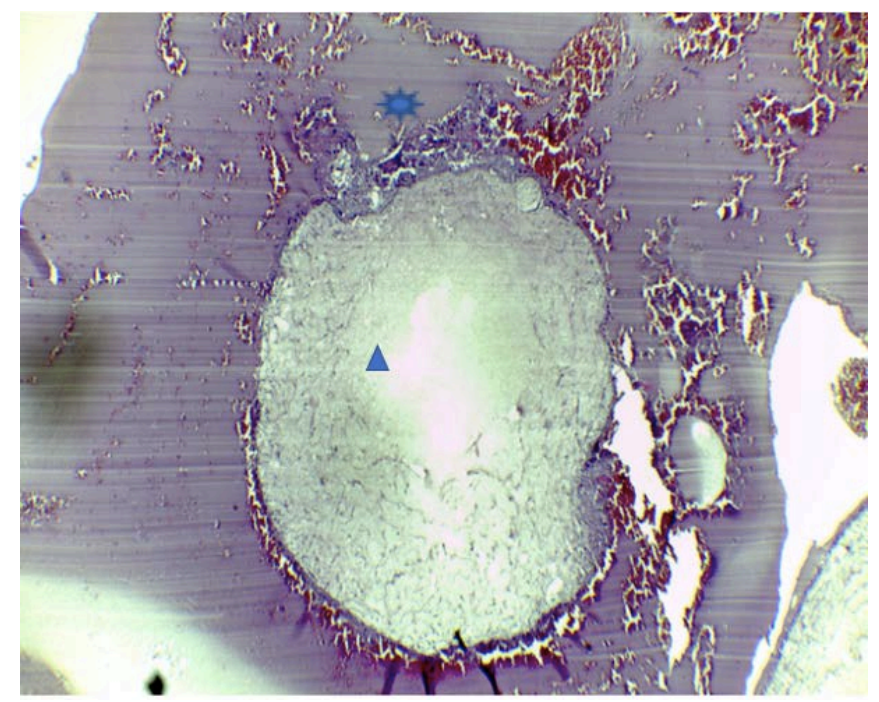

Figure 3. Hydropic chorionic villosities partially bordered by trophoblastic hyperplasia.

Beta HCG titration was done after histology results were obtained, i.e. 3 weeks after the operation. It came back below $2 \mathrm{mUI} / \mathrm{ml}$. The same result was obtained at 2 successive controls.

\section{Discussion}

Molar pregnancy is characterized by polycystic and hydropic degeneration of part or all of the chorionic villi and trophoblast proliferation with excessive secretion of chorionic gonadotropic hormone (CGH). This placental malformation is secondary to chromosomal aberrations occurring during gametogenesis and fertilization [2] [4]. Usually complete moles are diploid, due to fertilization of an empty ovum by a haploid spermatozoon. In $75 \%-85 \%$ of cases the karyotype is $\mathrm{XX}$ and in $15 \%-25 \%$ it is XY. Partial mole has 69 chromosomes (most often XXY) and corresponds to triploid syndrome (embryonic mole) [4] [5] [6]. As mentioned above, molar EP is rare, i.e. 1.5 cases out of 100,000 pregnancies. 
In Senegal, a study conducted in 1995 over 16 years found only two cases of molar EP [7]. However, this low incidence could be due to the fact that, at the time, the histology of salpingectomy parts or products of conception was not systematically performed. It should not be forgotten that the diagnosis of a molar ectopic pregnancy remains difficult, as there is nothing to differentiate it from a simple EP on the clinical or even biological level.

In our case, neither the clinical criteria nor the ultrasonographic and macroscopic criteria suggested an ectopic molar pregnancy. The initial diagnosis was therefore a simple ectopic pregnancy. Histology was the key to the diagnosis, hence the need to perform it before any product of conception.

Histology can also be a source of overdiagnosis because of the similarity between early tubal ectopic pregnancy and molar pregnancy [8]. Strict histopathological criteria must be used to ensure the accuracy of the diagnosis. DNA analysis by flow cytometry can also be performed [1] [8] [9].

The management of molar EP involves surgical removal of the product of conception either by salpingectomy or salpingotomy if the condition of the tube is favorable. The goal is to remove any trophoblastic residue. The reference approach remains laparoscopy.

In our case, a laparotomy was performed with complete removal of the affected tube. Monitoring of molar EP is not much different from intrauterine molar. It requires appropriate monitoring of beta-HCG titers. The aim is to detect any trophoblast residue and to exclude malignant trophoblastic disease. However, the occurrence of gestational trophoblastic disease after salpingectomy remains low or anecdotal compared to intrauterine mole (3.5\% to 20\%) [6].

Three successive beta-HCG controls were performed in our patient and came back negative. However, one undetectable HCG level after evacuation is sufficient.

\section{Conclusion}

Histology must be performed systematically for any product of conception in order not to fail to recognize a molar pregnancy. The latter may present as a tubal pregnancy. Molar pregnancy requires special follow-up, hence the importance of routine histology.

\section{Consent}

To ensure anonymity patient information was deidentified. Verbal consent was obtained from the patient.

\section{Conflicts of Interest}

The authors do not declare any conflict of interest.

\section{References}

[1] Sabre, A.M., Molina, A.D., Arul, M. and Elmadjian, M. (2019) Ectopic Molar Tubal 
Pregnancy: An Important Histological Presentation. International Journal of Medical Reviews and Case Reports, 3, 518-520. https://doi.org/10.1002/ccr3.2037

[2] Al-Maghrabi, H., Saleh, D. and Meliti, A. (2019) Gestational Trophoblastic Disease Presents as an Ectopic Tubal Pregnancy: A Rare Entity. Case Reports in Obstetrics and Gynecology, 2019, 7153170. https://doi.org/10.1155/2019/7153170

[3] Yakasai, I.A., Adamu, N. and Galadanchi, H.S. (2012) Ruptured Tubal Molar Pregnancy. Nigerian Journal of Clinical Practice, 15, 491-493. https://doi.org/10.4103/1119-3077.104537

[4] Leung, F., Terzibachian, J.J., Chung, F.B., Lassabe, C., Knoepffler, F., Maillet, R., et al. (2009) Môle hydatiforme hétérotopique ovarienne. A propos d'un cas [Heterotopic Ovarian Hydatidiform Mole. A Case Report]. Gynecologie, Obstetrique \& Fertilite, 37, 749-751. http://dx.doi.org/10.1016/j.gyobfe.2009.04.025

[5] Allen, L., Dawson, C., Nascu, P. and Rouse, T. (2016) A Molar Pregnancy within the Fallopian Tube. Case Reports in Obstetrics and Gynecology, 4367181. https://doi.org/10.1155/2016/4367181

[6] Mbarki, C., Jerbi, E., Hsayaoui, N., Zouari, F., Ben Brahim, E. and Oueslati, H. (2015) Molar Tubal Ectopic Pregnancy: Report of Two Cases. The Journal of Obstetrics and Gynaecology Research, 41, 985-988. https://doi.org/10.1111/jog.12642

[7] Diouf, A., Camara, A., Mendez, V., Rupari, L. and Diadhiou, F. (1995) Grossesse môlaire ectopique. A propos de deux observations en 16 ans [Ectopic Molar Pregnancy. Two Cases in Sixteen Years]. Contraception, Fertilite, Sexualite, 23, 674-676.

[8] Gupta, R., Gupta, N., Garg, R. and Puri, M. (2020) Ectopic Tubal Pregnancy with Partial Mole: A Rare Entity with Review of Literature. IP Journal of Diagnostic Pathology and Oncology, 5, 344-346. https://doi.org/10.18231/j.jdpo.2020.067

[9] Zhao, T., Hou, X., Su, C. and Wu, Q. (2019) Tubal Hydatidiform Mole Treated with Salpingotomy: A Case Report. Clinical Case Reports, 7, 653-655.

https://doi.org/10.1002/ccr3.2037 